\title{
Exercise four hour redistribution thallium-201 single photon emission computed tomography and exercise induced ST segment elevation in detecting the viable myocardium in patients with acute myocardial infarction
}

\author{
H Yamagishi, K Akioka, M Takagi, A Tanaka, K Takeuchi, J Yoshikawa, H Ochi
}

\begin{abstract}
Objective-To investigate the specificity and sensitivity of the combination of redistribution in exercise thallium-201 single photon emission computed tomography (SPECT) and exercise induced ST elevation for detecting the viable myocardium in patients with acute myocardial infarction.

Design-37 patients were studied within seven weeks of onset of $Q$ wave myocardial infarction (anterior in 22, inferior in 15). All patients underwent exercise four hour redistribution thallium-201 SPECT and positron emission tomography using fluorine-18-fluorodeoxyglucose (FDG) and nitrogen-13 ammonia under fasting conditions.

Results-Sixteen patients showed exercise induced ST elevation $\geqslant 1.5 \mathrm{~mm}$, and 15 of these had increased FDG uptake in the infarct region. Eleven of 16 patients (10 of 11 patients with anterior infarctions) with irreversible thallium-201 defects and increased FDG uptake showed exercise induced ST elevation. The sensitivity, specificity, and predictive accuracy of redistribution, exercise induced ST segment elevation, or both for detecting increased FDG uptake were $82 \%, 75 \%$, and $67 \%$ (94\%, $75 \%$, and $91 \%$ for anterior infarctions), respectively.

Conclusions-In patients with acute $Q$ wave myocardial infarction, the combination of redistribution in exercise thallium201 SPECT and exercise induced ST elevation can detect the viable myocardium in the infarct region with high sensitivity and specificity, especially in patients with anterior infarctions.

(Heart 1999;81:17-24)
\end{abstract}

Keywords: acute myocardial infarction; viability; exercise induced ST elevation; exercise thallium-201 SPECT

The differentiation of viable from non-viable myocardium in patients with myocardial infarction is important in deciding on the indications for revascularisation. Pohost et al have reported on the redistribution of thallium-201 in exercise thallium-201 myocardial scintigraphy, and this is considered to represent myocardial ischaemia. ${ }^{1}$ In many regions of the viable myocardium, however, the perfusion defects that were present on the initial images persist, appearing to be irreversible on delayed images obtained three to four hours after exercise. ${ }^{2}$ The defects are improved when an additional delayed image is obtained eight to 72 hours after thallium-201 injection, ${ }^{34}$ when a reinjection image is obtained, ${ }^{56}$ or when the resting study is repeated with an additional injection of thallium-201..$^{7}$

Myocardial glucose metabolic imaging by positron emission tomography (PET) has been proposed as a more sensitive technique for identifying metabolically viable myocardium. ${ }^{9}$ Thus conventional exercise four hour redistribution thallium-201 myocardial scintigraphy has a low sensitivity for detecting the viable myocardium in the region of the infarct.

Recently, Margonato et al reported that exercise induced ST segment elevation on infarct related electrocardiographic leads is closely associated with redistribution on thallium-201 myocardial scintigraphy. ${ }^{10}$ This ST segment elevation has a high specificity and sensitivity for detecting residual viability in the infarct area identified by PET with fluorine18-fluorodeoxyglucose (FDG) ${ }^{11}$

We now perform reinjection imaging in all exercise thallium-201 scans in patients with myocardial infarction. However, many laboratories have extensive exercise thallium-201 scintigraphic data without reinjection studies, performed before reinjection imaging became routine. Even then, though, electrocardiograms were routinely recorded during exercise thallium-201 scintigraphy. In our study we investigated the sensitivity and specificity of a combination of redistribution on conventional exercise four hour redistribution thallium-201 myocardial single photon emission computed tomography (SPECT) and exercise induced ST segment elevation for detecting viable myocardium in patients with acute myocardial infarction.

\section{Methods}

PATIENT POPULATION

We evaluated 37 patients with acute $Q$ wave myocardial infarction (32 men and five women; mean (SD) age 60 (10) years, range 35 to 75 years), who were admitted to the coronary care unit of Osaka City University Medical School Hospital from October 1993 to June 1996.
Accepted for publication 8 July 1998 
Acute myocardial infarction was diagnosed according to the presence of typical and prolonged chest pain, elevation of the ST segment on standard 12 lead electrocardiograms, and an increase in serum creatine kinase and/or the creatine kinase $\mathrm{MB}$ fraction to more than three times the normal upper limit. A Q wave infarct was defined as an acute myocardial infarct with the new appearance of a $\mathrm{Q}$ wave $(Q / R \geqslant 0.25)$ in more than one lead of the 12 lead electrocardiograms recorded serially after the onset of myocardial infarction. Patients who had had a previous myocardial infarct, previous coronary artery bypass grafting, or coronary angioplasty-except in the acute phase of myocardial infarction-were excluded. Patients with left ventricular hypertrophy, significant valvar disease, or left or right bundle branch block, and patients taking digitalis, were also excluded.

Of the 37 patients, 22 had anterior infarction and 15 had inferior infarction (including two lateral infarcts). Thirty two patients had one vessel disease, four had two vessel disease, and one had three vessel disease.

All patients underwent conventional exercise four hour redistribution myocardial thallium201 SPECT at 24 (9) days (range 7 to 46) after the onset of myocardial infarction, and PET using FDG and nitrogen-13 ammonia (NH3) at 23 (9) days (range 7 to 45 ) after onset. Two scintigraphic studies for each patient were performed within two weeks. All patients gave written informed consent.

\section{RADIOPHARMACEUTICALS}

Thallium-201 was obtained from commercial laboratories. A small cyclotron (NKK Corporation, Kanagawa, Japan) was used for the production of nitrogen-13 and fluorine-18. Then $\mathrm{NH} 3$ was produced according to the method described by Mulholland et $a l,{ }^{12}$ and FDG was synthesised using the method described by Hamacher et al. ${ }^{13}$

EXERCISE THALLIUM-201 SPECT

Each patient performed symptom limited exercise on a bicycle ergometer in the sitting position. Nitrates, $\beta$ adrenergic blockers, and calcium channel blockers were withheld on the morning of the test. Twelve-lead electrocardiograms and blood pressure measurements were obtained at baseline and every minute during exercise. The initial workload was 25 or 50 watts, and was increased 25 watts every two minutes until an end point was reached. The end points included excessive fatigue, dyspnoea, dizziness, moderate to severe angina, hypotension, diagnostic ST depression $(>1.5$ $\mathrm{mm}$ horizontal or downsloping or $>2.0 \mathrm{~mm}$ upsloping), or significant arrhythmia. By itself ST segment elevation in the infarct related leads was not considered to be a reason for terminating exercise. At peak exercise, a dose of $111 \mathrm{MBq}$ of thallium-201 was injected intravenously and the patient was encouraged to exercise for an additional minute. Initial images were obtained immediately after the termination of exercise, and delayed images were obtained four hours later.
The SPECT was performed using a single head gamma scintillation camera equipped with a low energy, all purpose, parallel hole collimator. Thirty two equidistant projections were acquired over $180^{\circ}$ from the right anterior oblique to the left posterior oblique at 25 seconds a projection. The images from the energy window of $70 \mathrm{keV} \pm 10 \%$ were collected in $64 \times 64$ matrices and then reconstructed using both Butterworth and Shepp and Rogan filters along the horizontal long axis and the vertical long axis of the heart. Images were normalised to the maximum count in each image set and displayed as colour scale images by a computer system (Scintipac-7000, Shimadzu Corporation, Kyoto, Japan). No attenuation correction was applied to SPECT.

PET IMAGING

For PET imaging, we used a Shimadzu-SET 1400 W-10 PET scanner (Headtome IV, Shimadzu Corporation, Kyoto, Japan). This scanner can obtain seven slices simultaneously with a $13 \mathrm{~mm}$ interval, slice thickness of $11 \mathrm{~mm}$ full width half maximum (FWHM), and spatial resolution of $4.5 \mathrm{~mm}$ FWHM. Axial, $6.5 \mathrm{~mm}$ interval $\mathrm{Z}$ motion of the scanner every minute provided a total of 14 contiguous transverse slices of the myocardium.

A 10 minute transmission scan was obtained using a rotating germanium-68 rod source. The acquired data were used to correct emission images for body attenuation. On completion of the attenuation scan, the patient remained in the supine position and received an intravenous injection of 259 to $740 \mathrm{MBq}$ of $\mathrm{NH} 3$. After a three minute delay to allow pulmonary background activity to clear, myocardial perfusion imaging was performed for 10 minutes.

After at least five hours of fasting and two to three hours after the perfusion scan was done, the patient received an intravenous injection of 148 to $407 \mathrm{MBq}$ of FDG. Sixty minutes were allowed for cardiac uptake of FDG. Imaging of glucose utilisation was then performed for 10 minutes.

Images were collected in $256 \times 256$ matrices and reconstructed by a computer system (Dr View, Asahi-Kasei Joho System Co, Tokyo, Japan) using Butterworth and Ramp filters along the horizontal long axis and the vertical long axis of the heart. Images were normalised to the maximum count in each image set and were displayed as colour scale images.

\section{CORONARY ARTERIOGRAPHY AND LEFT}

VENTRICULOGRAPHY

Three patients underwent successful coronary angioplasty of the infarct related artery within 24 hours of the onset of myocardial infarction. Both coronary arteriography and left ventriculography were performed in 33 patients at 26 (6) days (range 17 to 40 ) after the onset of myocardial infarction. One patient had only coronary arteriography. No coronary intervention was performed after 24 hours from the onset of myocardial infarction in any patient. Coronary arteriography and left ventriculography were performed using standard techniques. Biplane 


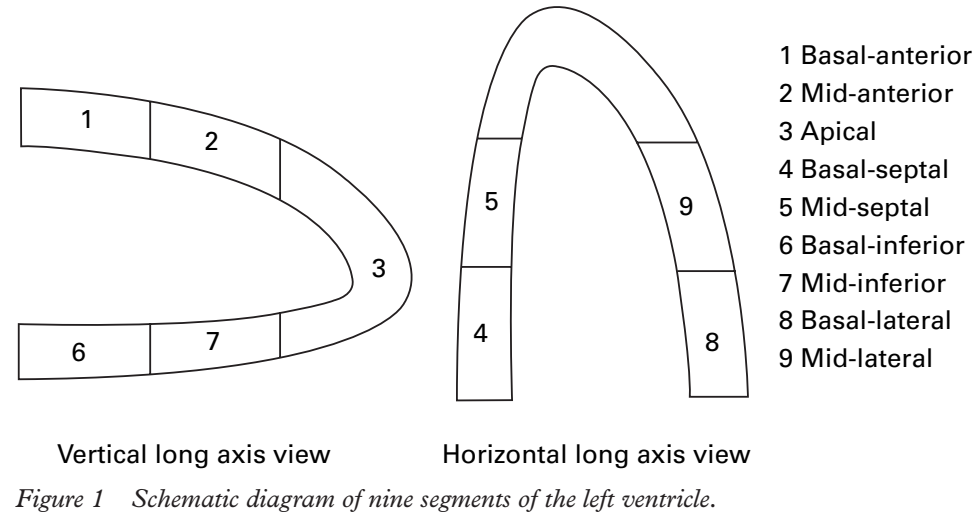

left ventriculography was performed in the $30^{\circ}$ right anterior oblique and $60^{\circ}$ left anterior oblique projections.

DATA ANALYSIS

Exercise induced ST segment elevation

The increment of exercise induced ST segment elevation $\geqslant 1.5 \mathrm{~mm}$ above the baseline at the $\mathrm{J}$ point in more than one electrocardiographic lead with a $\mathrm{Q}$ wave was considered significant. The presence of diagnostic ST segment depression in non-infarct related leads was also noted.

Assessment of images on exercise thallium-201 SPECT

On SPECT images, the left ventricular myocardium was divided into nine segments (basal anterior, mid-anterior, basal-septal, midseptal, basal inferior, mid-inferior, basallateral, mid-lateral, apical) on a vertical long axis slice and a horizontal long axis slice; a single segment representing the apex was assessed from the vertical long axis slice (fig 1). Anteroseptal-apical segments, inferior segments, and lateral segments were considered to be the left anterior descending artery territory, right coronary artery territory, and left circumflex artery territory, respectively.

The SPECT images were analysed individually by two experienced observers blinded to the patients' clinical data. Disagreements in interpretation were resolved by consensus of the two observers. Defects in each segment were scored using a five point grading system: 0 $=$ normal, $1=$ mild defect, $2=$ moderate defect, $3=$ severe defect, $4=$ no uptake. The severity score was calculated as the sum of defect scores of segments in the infarct territory. A decrease in the severity score of the delayed image compared with the severity score on the initial image indicated redistribution.

Comparison of NH3 and FDG on PET

Two experienced observers visually interpreted the uptake on $\mathrm{NH} 3$ and FDG images in segments, in a manner similar for analysis of SPECT. When FDG uptake in more than one segment in the infarct territory was definitely higher than in non-infarct territory, the patient was considered to have an ischaemic but viable myocardium in the infarct territory. ${ }^{14}$
Coronary arteriography and left ventriculography Coronary narrowing exceeding $50 \%$ was considered significant. The extent of retrograde collateral flow to stenosed vessels was graded according to the classification of Cohen and Rentrop. ${ }^{15}$

The left ventricular wall was divided into seven segments, and wall motion was graded according to recommendations of the American Heart Association, ${ }^{16}$ using the following four point scale: $0=$ normal, $1=$ hypokinesis, 2 $=$ akinesis, $3=$ dyskinesis. $\mathrm{A}$ global left ventricular wall motion abnormality index was calculated as the sum of the wall motion scores. These studies were assessed independently by two experienced observers blind to the other clinical data.

\section{Statistics}

Data are presented as mean (SD). Statistical significance of continuous variables was determined with the Student's $t$ test. The incidence of phenomena was compared by the $\chi^{2}$ test. Left ventricular wall motion abnormality indices were compared by the Wilcoxon rank-sum test. Probability $(\mathrm{p})$ values $<0.05$ were considered statistically significant.

\section{Results}

ST SEGMENT ELEVATION AND CLINICAL DATA

Sixteen patients had significant exercise induced ST segment elevation (mean 2.2 (0.7) $\mathrm{mm}$, range 1.5 to $4 \mathrm{~mm}$ ) in more than one infarct related lead (group A). The other 21 patients had no significant exercise induced ST segment elevation in any infarct related lead (group B).

As seen in table 1 , there were no significant differences in age, sex, pressure-rate product at peak exercise, presence of redistribution on exercise thallium-201 SPECT, the incidence of severe irreversible defect (mean defect score $>3$ ), number of diseased vessels, percentage stenosis of the infarct related artery, collateral flow to the infarct related artery, presence of dyskinetic segments, or global left ventricular wall motion abnormality index between group $\mathrm{A}$ and group B. The incidences of anterior infarction and ST elevation $>1.0 \mathrm{~mm}$ in more than one electrocardiographic lead with a $\mathrm{Q}$ wave at rest were higher in group A than in group B. The incidence of exercise induced ST depression was higher in group B than in group A.

Relations among exercise induced ST elevation, redistribution, and increased FDG uptake are summarised in table 2 . Fifteen $(94 \%)$ of the 16 patients in group A and $13(62 \%)$ of the 21 patients in group B $(p<0.05)$ had increased FDG uptake in the infarct related territory on the PET study. Increased FDG uptake in anteroseptal-apical segments was seen in 14 patients in group A (93\%) and four in group B $(57 \%)(\mathrm{p}<0.05)$. As with inferior infarctions, the one patient in group A $(100 \%)$ and nine of 14 patients in group B (64\%) (NS) showed an increase in FDG uptake in the inferolateral segments.

The sensitivity, specificity, and predictive accuracy of exercise induced ST segment elevation for detecting the viable myocardium 
Table 1 Comparison of clinical data in groups $A$ and $B$

\begin{tabular}{|c|c|c|c|}
\hline & Group $A$ & Group B & $p$ value \\
\hline Number of patients & 16 & 21 & \\
\hline Age (years) (mean (SD)) & $57(11)$ & $62(10)$ & NS \\
\hline Sex: male/female & $14 / 2$ & $18 / 3$ & NS \\
\hline Location of infarction: anterior/inferior & $15 / 1$ & $7 / 14$ & $<0.001$ \\
\hline $\begin{array}{l}\text { Pressure-rate product at peak exercise (mm Hg.beats/min) } \\
\text { (mean (SD)) }\end{array}$ & $24088(4561)$ & $22146(5167)$ & NS \\
\hline \multicolumn{4}{|l|}{ ST elevation $>1.0 \mathrm{~mm}$ on resting ECG } \\
\hline $\begin{array}{l}\text { present }(\%) / \text { absent }(\%) \\
\text { Exercise induced ST depression present }(\%) / \text { absent }(\%)\end{array}$ & $\begin{array}{l}7(44 \%) / 9(56 \%) \\
2(13 \%) / 14(87 \%)\end{array}$ & $\begin{array}{l}2(10 \%) / 19(90 \%) \\
9(43 \%) / 12(57 \%)\end{array}$ & $\begin{array}{l}<0.05 \\
<0.05\end{array}$ \\
\hline Redistribution on exercise SPECT present (\%)/absent (\%) & $4(25 \%) / 12(75 \%)$ & $10(48 \%) / 11(52 \%)$ & NS \\
\hline Irreversible defect mean defect score $\leqslant 3 />3$ & $3 / 9$ & $3 / 8$ & NS \\
\hline \multicolumn{4}{|l|}{ Number of diseased vessels } \\
\hline One vessel disease $(\%)$ & $15(94 \%)$ & $17(71 \%)$ & \\
\hline Two vessel disease (\%) & $1(6 \%)$ & $3(14 \%)$ & \\
\hline Three vessel disease (\%) & 0 & $1(5 \%)$ & NS \\
\hline \multicolumn{4}{|l|}{$\%$ Stenosis of infarct related artery } \\
\hline $100 \%$ & 5 & 6 & \\
\hline$\leqslant 99 \%$ & 0 & 4 & \\
\hline$\leqslant 90 \%$ & 6 & 6 & \\
\hline$\leqslant 50 \%$ & 3 & 4 & \\
\hline Unknown & 2 & 1 & NS \\
\hline \multicolumn{4}{|l|}{ Collateral flow to infarct related artery } \\
\hline Grade 3 & 0 & 2 & \\
\hline Grade 2 & 1 & 3 & \\
\hline Grade 1 & 1 & 3 & \\
\hline Grade 0 & 12 & 12 & \\
\hline Unknown & 2 & 1 & NS \\
\hline Dyskinetic segment present (\%)/absent (\%) & $7(50 \%) / 7(50 \%)$ & $5(26 \%) / 14(74 \%)$ & NS \\
\hline $\begin{array}{l}\text { Global left ventricular wall motion abnormality index } \\
\text { (mean (SD)) }\end{array}$ & $5.9(1.8)$ & $5.4(2.9)$ & NS \\
\hline
\end{tabular}

Group A, patients with exercise induced ST segment elevation; group B, patients without exercise induced ST segment elevation.

were $54 \%, 89 \%$, and $62 \%$, respectively. For anterior infarcts, the values were $78 \%, 75 \%$, and $77 \%$, respectively. For inferior infarcts, values were $10 \%, 100 \%$, and $40 \%$, respectively.

The sensitivity, specificity, and predictive accuracy of ST segment elevation at rest for detecting the viable myocardium were $25 \%$, $78 \%$, and $38 \%$, respectively.

Of 11 patients with exercise induced ST depression, seven showed increased FDG uptake in infarct related territory (NS v patients not showing exercise induced ST depression).

REDISTRIBUTION ON EXERCISE THALLIUM-201 SPECT AND CLINICAL DATA

Fourteen patients showed redistribution on exercise thallium-201 myocardial SPECT (group X). The other 23 patients did not show

Table 2 Relations among exercise induced ST elevation, redistribution, and increased FDG uptake

\begin{tabular}{|c|c|c|c|c|c|}
\hline & & & Total & Group $A$ & Group B \\
\hline \multirow[t]{6}{*}{ All patients } & \multirow[t]{3}{*}{ Group X } & Increased FDG uptake (+) & 12 & 4 & 8 \\
\hline & & Increased FDG uptake (-) & 2 & 0 & 2 \\
\hline & & Total & 14 & 4 & 10 \\
\hline & \multirow[t]{3}{*}{ Group Y } & Increased FDG uptake (+) & 16 & 11 & 5 \\
\hline & & Increased FDG uptake $(-)$ & 7 & 1 & 6 \\
\hline & & Total & 23 & 12 & 11 \\
\hline \multirow{6}{*}{ Anterior MI } & \multirow[t]{3}{*}{ Group X } & Increased FDG uptake (+) & 7 & 4 & 3 \\
\hline & & Increased FDG uptake (-) & 0 & 0 & 0 \\
\hline & & Total & 7 & 4 & 3 \\
\hline & \multirow[t]{3}{*}{ Group Y } & Increased FDG uptake (+) & 11 & 10 & 1 \\
\hline & & Increased FDG uptake $(-)$ & 4 & 1 & 3 \\
\hline & & Total & 15 & 11 & 4 \\
\hline \multirow{6}{*}{ Inferior MI } & \multirow[t]{3}{*}{ Group X } & Increased FDG uptake (+) & 5 & 0 & 5 \\
\hline & & Increased FDG uptake $(-)$ & 2 & 0 & 2 \\
\hline & & Total & 7 & 0 & 7 \\
\hline & \multirow[t]{3}{*}{ Group Y } & Increased FDG uptake (+) & 5 & 1 & 4 \\
\hline & & Increased FDG uptake (-) & 3 & 0 & 3 \\
\hline & & Total & 8 & 1 & 7 \\
\hline
\end{tabular}

Values are numbers of patients.

Group A, patients with exercise induced ST segment elevation; group B, patients without exercise induced ST segment elevation; group X, patients with redistribution on exercise thallium-201 scan; group Y, patients without redistribution on exercise thallium-201 scan; (+), present; (-), absent. MI, myocardial infarction. redistribution on exercise thallium-201 SPECT (group Y).

There were no significant differences in age, sex, location of infarction, pressure-rate product at peak exercise, presence of exercise induced ST segment elevation or depression, number of diseased vessels, percentage stenosis of the infarct related artery, collateral flow to the infarct related artery, or global left ventricular wall motion abnormality index between group $\mathrm{X}$ and group $\mathrm{Y}$ (table 3 ). However, dyskinetic segments were observed more often in group $\mathrm{Y}$ than in group $\mathrm{X}(\mathrm{p}<0.05)$.

Twelve patients in group $\mathrm{X}(86 \%)$ and 16 patients in group $\mathrm{Y}(70 \%)$ (NS) showed increased FDG uptake in the infarct related territory on the PET study. In group Y, 11 $(69 \%)$ of 16 patients with increased FDG uptake and one (14\%) of seven without increased FDG uptake $(\mathrm{p}<0.05)$ had exercise induced ST elevation. When only anterior infarcts were analysed, seven patients in group $\mathrm{X}$ $(100 \%)$ and 11 in group Y (73\%) (NS) had increased FDG uptake in anteroseptal-apical segments. Among patients in group $\mathrm{Y}$ with anterior infarction, $10(91 \%)$ of 11 patients with increased FDG uptake, and one $(25 \%)$ of four without increased FDG uptake ( $\mathrm{p}<0.05$ ) had exercise induced ST elevation. When only inferior infarcts were analysed, four patients in group $\mathrm{X}(67 \%)$ and five in group $\mathrm{Y}(63 \%)$ (NS) showed increased FDG uptake in inferolateral segments. Among patients in group Y with inferior infarction, one of four patients with increased FDG uptake and none of four without (NS) showed exercise induced ST elevation.

The sensitivity, specificity, and predictive accuracy of redistribution on exercise thallium201 SPECT for detecting the viable myocardium were $43 \%, 78 \%$, and $51 \%$, respectively. 
Table 3 Comparison of clinical data in groups $X$ and $Y$

\begin{tabular}{|c|c|c|c|}
\hline & Group $X$ & Group Y & p Value \\
\hline Number of patients & 14 & 23 & \\
\hline Age (years) (mean (SD)) & $61(8)$ & $59(12)$ & NS \\
\hline Sex: male/female & $11 / 3$ & $21 / 2$ & NS \\
\hline Location of infarction: anterior/inferior & $7 / 7$ & $15 / 8$ & NS \\
\hline \multicolumn{4}{|l|}{ Pressure-rate product at peak exercise ( $\mathrm{mm} \mathrm{Hg}$.beats $/ \mathrm{min}$ ) } \\
\hline$($ mean $(\mathrm{SD}))$ & $23997(5136)$ & $22370(4835)$ & NS \\
\hline Exercise induced ST elevation present (\%)/absent (\%) & $4(29 \%) / 10(71 \%)$ & $12(52 \%) / 11(48 \%)$ & NS \\
\hline Exercise induced ST depression present $(\%) /$ absent (\%) & $6(43 \%) / 8(57 \%)$ & $5(22 \%) / 18(78 \%)$ & NS \\
\hline \multicolumn{4}{|l|}{ Number of diseased vessels } \\
\hline One vessel disease $(\%)$ & $10(71 \%)$ & $22(96 \%)$ & \\
\hline Two vessel disease $(\%)$ & $3(21 \%)$ & $1(4 \%)$ & \\
\hline Three vessel disease (\%) & $1(7 \%)$ & 0 & NS \\
\hline \multicolumn{4}{|l|}{$\%$ Stenosis of infarct related artery } \\
\hline $100 \%$ & 2 & 9 & \\
\hline$\leqslant 99 \%$ & 3 & 1 & \\
\hline$\leqslant 90 \%$ & 6 & 6 & \\
\hline$\leqslant 50 \%$ & 2 & 5 & \\
\hline Unknown & 1 & 2 & NS \\
\hline \multicolumn{4}{|l|}{ Collateral flow to infarct related artery } \\
\hline Grade 3 & 1 & 1 & \\
\hline Grade 2 & 3 & 1 & \\
\hline Grade 1 & 1 & 3 & \\
\hline Grade 0 & 8 & 16 & \\
\hline Unknown & 1 & 2 & NS \\
\hline Dyskinetic segment present (\%)/absent (\%) & $2(17 \%) / 12(83 \%)$ & $10(48 \%) / 11(52 \%)$ & $<0.05$ \\
\hline $\begin{array}{l}\text { Global left ventricular wall motion abnormality index (mean } \\
\text { (SD)) }\end{array}$ & $5.0(2.8)$ & $6.0(2.3)$ & NS \\
\hline
\end{tabular}

Group X, patients with redistribution on exercise thallium-201 scan; group Y, patients without redistribution on exercise thallium201 scan.

These values in patients with anterior infarcts were $39 \%, 100 \%$, and $50 \%$, respectively. For inferior infarcts, respective values were $50 \%$, $60 \%$, and $53 \%$.

In 28 patients with increased FDG uptake, 17 showed redistribution or a mild irreversible defect (mean defect score $\leqslant 3$ ), or both. In nine patients without increased FDG uptake, four showed a mild irreversible defect. The sensitivity, specificity, and predictive accuracy of the combination of mild irreversible defect and redistribution on exercise thallium-201 SPECT for detecting the viable myocardium were $61 \%, 44 \%$, and $57 \%$, respectively.

COMBINATION OF EXERCISE INDUCED ST SEGMENT ELEVATION AND REDISTRIBUTION ON EXERCISE THALLIUM-201 SPECT

Data are shown in table 4 . Overall, 26 patients showed redistribution on exercise thallium-201 SPECT, exercise induced ST segment elevation, or both (group P), and 11 showed neither of the two phenomena (group N). Eighteen patients in group $\mathrm{P}$ and four in group $\mathrm{N}$ had anterior infarcts (NS). While 23 patients in group $\mathrm{P}(88 \%)$ had increased FDG uptake in the infarct related territory, only five $(45 \%)$ in group $\mathrm{N}$ had increased uptake $(\mathrm{p}<0.05)$. When only anterior infarcts were analysed, 17 patients in group $\mathrm{P}(94 \%)$ and one in group $\mathrm{N}$ $(25 \%)$ showed increased FDG uptake $(\mathrm{p}<0.05)$. When only inferior infarcts were analysed, six patients in group $\mathrm{P}(75 \%)$ and four in group $\mathrm{N}(57 \%)$ showed increased FDG uptake (NS).

The sensitivity, specificity, and predictive accuracy of the combination of redistribution on exercise thallium-201 SPECT and exercise induced ST segment elevation for detecting the viable myocardium were $82 \%(\mathrm{p}<0.005 v$ only redistribution), $75 \%$ (NS), and $67 \%$ $(\mathrm{p}<0.01)$, respectively. These values in $\mathrm{pa}-$ tients with anterior infarcts were $94 \%$ ( $\mathrm{p}<0.0005 v$ only redistribution), $75 \%$ (NS), and $91 \%(\mathrm{p}<0.005)$, respectively. In patients with inferior infarcts, respective values were $60 \%, 60 \%$, and $60 \%$ (all NS $v$ only redistribution), respectively.

\section{Discussion}

In this study, $94 \%$ of the patients with exercise induced ST elevation showed increased FDG uptake in the infarct territory. The presence of redistribution on conventional exercise

Table 4 Relations between the combination of exercise induced ST elevation and redistribution, and increased FDG uptake

\begin{tabular}{|c|c|c|c|c|c|c|c|c|}
\hline & & Total & Group P & Group $N$ & $p$ Value & $\begin{array}{l}\text { Sensitivity } \\
(\%)\end{array}$ & $\begin{array}{l}\text { Specificity } \\
(\%)\end{array}$ & $\begin{array}{l}\text { Predictive } \\
\text { accuracy } \\
(\%)\end{array}$ \\
\hline \multirow[t]{3}{*}{ All patients } & Increased FDG uptake (+) & 28 & 23 & 5 & & & & \\
\hline & Increased FDG uptake (-) & 9 & 3 & 6 & $<0.05$ & 82 & 75 & 67 \\
\hline & Total & 37 & 26 & 11 & & & & \\
\hline \multirow[t]{3}{*}{ Anterior MI } & Increased FDG uptake (+) & 18 & 17 & 1 & & & & \\
\hline & Increased FDG uptake (-) & 4 & 1 & 3 & $<0.05$ & 94 & 75 & 91 \\
\hline & Total & 22 & 18 & 4 & & & & \\
\hline \multirow[t]{3}{*}{ Inferior MI } & Increased FDG uptake (+) & 10 & 6 & 4 & & & & \\
\hline & Increased FDG uptake (-) & 2 & 2 & 3 & NS & 60 & 60 & 60 \\
\hline & Total & 15 & 8 & 7 & & & & \\
\hline
\end{tabular}

Values are numbers of patients.

Group P, patients with exercise induced ST segment elevation, redistribution on exercise thallium-201 scan, or both; group N, patients with neither exercise induced ST segment elevation nor redistribution on exercise thallium-201 scan; (+), present; (-), absent. MI, myocardial infarction. 
thallium-201 SPECT, exercise induced ST elevation in infarct related leads, or both, in patients with an acute $Q$ wave infarct has a high sensitivity, specificity, and predictive accuracy for detecting viable myocardium, especially in patients with an anterior infarct.

Dilsizian et al reported that $42(49 \%)$ of 85 irreversible regions on three to four hour delayed images on exercise thallium-201 SPECT showed an improved or normal uptake of thallium-201 after a second injection. ${ }^{6}$ Tamaki et al reported that 26 (54\%) of 48 abnormal segments without redistribution on conventional three hour delayed images showed ischaemia on PET, and 19 $(73 \%)$ of them had new fill-in after the reinjection of thallium-201. ${ }^{17}$ Bonow et al reported the uptake of FDG uptake in 121 $(73 \%)$ of 166 segments with irreversible defects on conventional four hour delayed images on exercise scintigraphy, of which 69 segments $(57 \%)$ showed new fill-in after thallium-201 reinjection. ${ }^{9}$ Kiat et al found late reversibility on 18 to 72 hour delayed images in $74(61 \%)$ of 122 regions irreversible on four hour delayed image on exercise thallium-201 SPECT. ${ }^{4}$

In our study, $68 \%$ of patients with irreversible defects on conventional exercise four hour redistribution myocardial SPECT and increased FDG uptake in the infarct related territory showed exercise induced ST elevation. In patients with anterior infarction, $91 \%$ of those with irreversible defects and an increase in FDG uptake had exercise induced ST elevation. These results are comparable with the previous reports of detection of viable myocardium in irreversible defects on conventional exercise thallium-201 SPECT after the reinjection of thallium-201, or on 18 to 72 hour delayed images.

Many investigators have explored whether exercise induced ST elevation in patients with previous myocardial infarction is caused by myocardial ischaemia or left ventricular wall motion abnormality. Waters et al reported that exercise induced ST elevation was associated with dyskinetic or akinetic myocardial segments. ${ }^{18}$ According to Weiner et al, exercise induced ST elevation without ST depression suggested single vessel disease and left ventricular aneurysm. ${ }^{19}$ Chahine et al and Sriwattanakomen et al felt that exercise induced ST elevation reflected the presence of severe coronary artery disease and left ventricular aneurysm. ${ }^{20}{ }^{21}$ Fox et al reported that coronary artery bypass grafting abolished exercise induced ST elevation and symptoms in 11 of 19 patients, suggesting the importance of exercise induced ST elevation in myocardial ischaemia. ${ }^{22}$ Dunn et al reported that the exercise induced ST elevation corresponded to severe coronary artery stenosis, abnormal left ventricular wall motion, and a thallium-201 defect (either a fixed defect on four hour delayed image or redistribution), suggesting that exercise induced ST elevation may due to peri-infarctional ischaemia, abnormal ventricular wall motion, or both. ${ }^{23}$ Other investigators, using conventional exercise redistribution thallium-201 scanning for detecting myocardial ischaemia, suggested that the mechanism for the exercise induced ST elevation might be mechanical rather than related to myocardial ischaemia. ${ }^{24-26}$ The disagreement between previous and recent data regarding the mechanism of exercise induced ST elevation may be related to the current widespread use of thrombolysis in the acute phase of myocardial infarction, resulting in more residual viability. Conventional exercise redistribution thallium-201 scintigraphy can miss the presence of myocardial ischaemia in many patients, and it can be detected only by reinjection of thallium-201 or by FDG PET. $^{59}$ However, mild irreversible thallium201 defects reflect viability, although they may not reflect inducible ischaemia. The lack of a difference in the incidence redistribution between groups A and B in our study is consistent with previous reports. ${ }^{24}{ }^{25} 27$ We used PET with FDG, a marker of exogenous glucose uptake, for detecting the viable myocardium. This tracer has been reported to detect residual viability more sensitively than the reinjection of thallium-201 $1^{9}$ and to predict the potential reversibility of wall motion abnormalities following revascularisation. ${ }^{28} 29$ Our results showed that exercise induced ST elevation was closely associated with the presence of a viable myocardium in the infarct territory.

Margonato et al reported that $94 \%$ of patients with, and $50 \%$ of patients without, exercise induced ST elevation showed reversible defects on conventional exercise thallium201 planar scintigraphy within six months of myocardial infarction. ${ }^{10}$ Their incidence of redistribution in patients with exercise induced ST elevation was much higher than in other reports. ${ }^{23}{ }^{24}$ Margonato et al considered the difference to be caused by the short interval between the myocardial infarction and the exercise testing, and the high incidence (59\%) of patent infarct related coronary arteries. In the present study, which was performed in an earlier phase of myocardial infarction (less than seven weeks), only $33 \%$ of patients showed redistribution, and $56 \%$ of patients with exercise induced ST elevation had patent infarct related arteries. The incidence of redistribution in patients with exercise induced ST elevation in the present study resembled that found in other previously reported studies, ${ }^{23} 24$ though not that of Margonato et al. ${ }^{10}$ Tamaki et al observed new fill-in after reinjection in segments with persistent defects on three hour delayed images more often in the segments with an increased FDG uptake than in segments without increased FDG uptake. ${ }^{17}$ The incidence of redistribution in the present study may have been influenced by the incidence of increased FDG uptake in the patients.

Although half of our patients with exercise induced ST elevation had a dyskinetic segment, $94 \%$ of this group had residual viable myocardium in the infarct region, which suggests that the wall motion abnormalities are potentially reversible after revascularisation. ${ }^{28}{ }^{29}$ The absence of exercise induced ST elevation did not rule out the presence of viable myocardium. In the present study, $62 \%$ of the 
patients without exercise induced ST elevation showed an increased FDG uptake. Such observations were also reported by Margonato et al. ${ }^{11}$

The sensitivity, specificity, and predictive accuracy were lower in the patients with inferior infarcts than in those with anterior infarcts. This may be caused by the influence of diaphragmatic attenuation of visual analysis of thallium-201 defects in inferior walls, or the dual blood supply to the inferior wall.

Exercise induced ST depression was not related to exercise induced ST elevation or increased FDG uptake in infarct related territory in the present study. Exercise induced ST depression was considered to be related to exercise induced ischaemia in infarct related territory or remote areas, but not to myocardial viability.

Three of our 28 patients with viable myocardium in the infarct territory underwent successful angioplasty in the acute phase of infarction, and five had stenosis of the infarct related artery of less than $50 \%$. In these patients, the ischaemia indicated by an increased FDG uptake could not result from limitation of blood flow from stenosis of the epicardial coronary artery. Schofer et al reported a scintigraphic no-reflow phenomenon after thrombolysis. ${ }^{30}$ Myocardial ischaemia without significant stenosis of the coronary artery may be caused by no-reflow or by obstruction of microvessels in the infarct region.

Gropler et al reported that FDG uptake under fasting conditions might underestimate tissue viability. ${ }^{31}$ We did not investigate serial changes in left ventricular wall motion abnormality. That would be necessary to confirm whether FDG uptake under fasting conditions detected by redistribution or exercise induced ST elevation may indicate the potential reversibility of the wall motion abnormalities after revascularisation. We assessed SPECT and PET images visually in only a small number of patients. To confirm our results, quantitative analysis in a larger patient population should be performed.

\section{CONCLUSION}

In conclusion, the combination of conventional exercise redistribution thallium-201 myocardial SPECT and exercise induced ST elevation can detect ischaemic but viable myocardium in patients with acute $\mathrm{Q}$ wave myocardial infarction with high sensitivity and specificity, especially in patients with anterior infarction. Analysis of exercise induced ST elevation is very simple, and this is an inexpensive and widely available diagnostic procedure.

1 Pohost GM, Zir LM, Moore RH, et al. Differentiation of transiently ischemic from infarcted myocardium by serial imaging after a single dose of thallium-201. Circulation 1977;55:294-302

2 Brunken RC, Kotou S, Nienaber CA, et al. PET detection of viable tissue in myocardial segments with persistent of viable tissue in myocardial segments with persister

3 Cloninger KG, DePuey EG, Garcia EV, et al. Incomplete redistribution in delayed thallium-201 single photon emission computed tomography (SPECT) images: an overestimation of myocardial scarring. $\mathcal{F}$ Am Coll Cardiol 1988;12 955-63.
4 Kiat H, Berman DS, Maddahi J, et al. Late reversibility of tomographic myocardial thallium-201 defects: an accurate tomographic myocardial thallium-201 defects: an accurate marker of

5 Rocco TP, Dilsizian V, McKusick KA, et al. Comparison of thallium redistribution with rest "reinjection" imaging for the detection of viable myocardium. Am f Cardiol 1990;66: 158-63.

6 Dilsizian V, Rocco TP, Freedman NMT, et al. Enhanced detection of ischemic but viable myocardium by the reinjection of thallium after stress-redistribution imaging. N Engl F Med 1990;323:141-6.

7 Blood DK, McCarthy DM, Sciacca RR, et al. Comparison of single-dose and double-dose thallium-201 myocardial perfusion scintigraphy for the detection of coronary artery disease and prior myocardial infarction. Circulation 1978; 58:777-88.

8 Ritchie JL, Albro PC, Caldweel JH, et al. Thallium-201 myocardial imaging: a comparison of the redistribution and rest images. $\mathcal{F}$ Nucl Med 1979;20:477-83.

9 Bonow RO, Dilsizian V, Cuocolo A, et al. Identification of viable myocardium in patients with chronic coronary artery disease and left ventricular dysfunction. Comparison of thallium scintigraphy with reinjection and PET imaging with 18F-fluorodeoxyglucose. Circulation 1991;83:26-37.

10 Margonato A, Ballarotto C, Bonetti F, et al. Assessment of residual tissue viability by exercise testing in recent myocardial infarction: comparison of electrocardiogram and myocardial perfusion scintigraphy. $\mathcal{f} \mathrm{Am}$ Coll Cardiol 1992;19:948-52.

11 Margonato A, Chierchia SL, Xuereb RG, et al. Specificity and sensitivity of exercise-induced ST segments elevation for detection of residual viability: comparison with fluorodeoxyglucose and positron emission tomography. $\mathcal{f}$ Am Coll Cardiol 1995;25:1032-8.

12 Mulholland GK, Kilbourn MR, Moskwa JJ. Direct simultaneous production of [15O]water and [13N]ammonia or $[18 \mathrm{~F}]$ fluoride ion by $26 \mathrm{MeV}$ proton irradiation of a double chamber water target. Appl Radiat Isot 1990;41:1193-9.

13 Hamache K, Coenen HH, Stocklin G. Efficient stereospecific synthesis of no-carrier-added 2-[18F]-fluoro-2-deoxyD-glucose using aminopolyether supported nucleophilic D-glucose using aminopolyether supported
substitution. F Nucl Med 1986;27:235-8.

14 Tamaki N, Yonekura Y, Yamashita K, et al. Positron emission tomography using fluorine-18 deoxyglucose in evaluating of coronary artery bypass grafting. Am $\mathcal{F}$ Cardiol 1989;64:860-5.

15 Cohen M, Rentrop KP. Limitation of myocardial ischemia by collateral circulation during sudden controlled coronary occlusion in human subject: a prospective study. Circulation 1986;74:469-76.

16 American Heart Association Committee Report. A reporting system on patients evaluated for coronary artery disease. Circulation 1975;51:7-12.

17 Tamaki N, Ohtani H, Yamshita K, et al. Metabolic activity in the areas of new fill-in after thallium-201 reinjection: comparison with positron emission tomography using fluorineparison with positron emission tomography us

18 Waters DD, Chaitman BR, Bourassa MG, et al. Clinical and angiographic correlates of exercise-induced ST-segment angiographic correlates of exercise-induced ST-segment Circulation 1980;61:286-96.

19 Weiner DA, McCabe C, Klein MD, et al. ST segment changes post-infarction: predictive value for multivessel coronary disease and left ventricular aneurysm. Circulation 1978;58:887-91.

20 Chahine RA, Raizner AE, Ishimori T. The clinical significance of exercise-induced ST segment elevation. Circulation 1976;54:209-13.

21 Sriwattanakomen S, Ticzon AR, Zubritzky SA, et al. S-T segment elevation during exercise: electrocardiographic and arteriographic correlation in 38 patients. Am f Cardiol 1980;45:762-8.

22 Fox KM, Jonathan A, Selwyn A. Significance of exercise induced ST segment elevation in patients with previous myocardial infarction. Br Heart f 1983;49:15-19.

23 Dunn RF, Bailey IK, Uren R, et al. Exercise-induced Dunn RF, Bailey IK, Uren R, et al. Exercise-induced dial perfusion scanning and coronary arteriography. Circudial perfusion scanning

24 Lahiri A, Balasubramanian V, Craig MWM, et al. Exerciseinduced ST segment elevation. Electrocardiographic, angiographic and scintigraphic evaluation. Br Heart ff 1980;43: $582-8$.

25 Gewirtz H, Sullivan M, O'Reilly G, et al. Role of myocardial ischemia in the genesis of stress-induced S-T segment elevation in previous anterior myocardial infarction. $A m \mathcal{F}$ Cardiol 1983;51:1289-93.

26 Ogawa $\mathrm{T}$, Ishii $\mathrm{M}$, Iida $\mathrm{K}$, et al. Mechanisms of stress-induced ST elevation and negative T-wave normalization studied by serial cardiokymogram in patients with a previous myocardial infarction. Am f Cardiol 1990;65:962-6.

27 Haines DE, Beller GA, Watson DD, et al. Exercise-induced ST segment elevation 2 weeks after uncomplicated myocardial infarction: contributing factors and prognostic myocardial infarction: contributing factors and p

28 Tillisch J, Brunken R, Marshall R, et al. Reversibility of cardiac wall-motion abnormalities predicted by positron tomography. N Engl f Med 1986;314:884-8.

29 Pierard LA, De Landsheere CM, Berthe C, et al. Identification of viable myocardium by echocardiography during dobutamine infusion in patients with myocardial infarction after thrombolytic therapy: comparison with positron emission tomography. F Am Coll Cardiol 1990;15:1021-31. 
30 Schofer J, Monts R, Mathey DG. Scintigraphic evidence of the "no-reflow" phenomenon in human beings after coronary thrombolysis. F Am Coll Cardiol 1985;5:593-8.
31 Gropler RJ, Siegel BA, Lee KJ, et al. Nonuniformity in myocardial accumulation of fluorine-18-fluorodeoxyglucose in normal fasted humans. 7 Nucl Med 1990;31:1749-56.

\section{IMAGES IN CARDIOLOGY}

\section{Systemic embolism during coronary artery bypass surgery}

A 71 year old white man with a history of ischaemic heart disease with severe three vessel coronary artery disease and congestive heart failure (left ventricular ejection fraction $<30 \%$ ) was scheduled for coronary artery bypass grafting using warm blood cardioplegia.

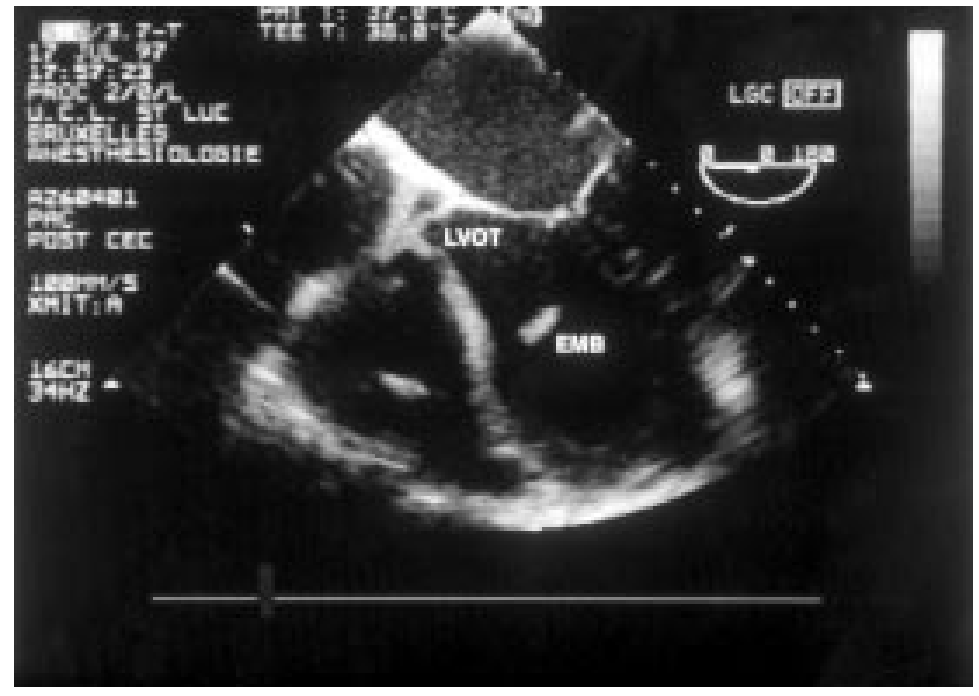

Routine perioperative transoesophageal echocardiography after weaning off cardiopulmonary bypass uncovered an impending intracardiac thrombus, first caught in the subvalvar apparatus of the posterior mitral valve leaflet, later presenting as a free floating left ventricular mass (LVOT, left ventricular outflow tract; $\mathrm{EMB}$, intracardiac thrombus).

The oval structure, not seen at preoperative transthoracic or transoesophageal echocardiography, rapidly disappeared in the blood flow before extracorporeal circulation could be reinstituted. Further echocardiographic evaluation failed to localise the thrombus in a cardiac chamber or in the aorta. An extensive search for systemic embolisation into the peripheral arterial circulation was performed. No anisocoria was noted but a postoperative continuous Doppler flow analysis of the lower limbs revealed a possible embolism to the left tibial artery, threatening the viability of the extremity. Fortunately, distal flow in the left lower limb was successfully restored after embolectomy using a Fogarthy catheter. The patient made an uneventful recovery and was left with no long term sequelae.

P VRANCKX M VAN DYCK Y DUDEKEM 